\title{
ANALISIS NILAI RELIGIUS DALAM NOVEL KETIKA MAS GAGAH PERGI KARYA HELVY TIANA ROSA
}

\author{
Jepri Arizal \\ Penulis adalah Dosen Sekolah Tinggi Keguruan dan Ilmu Pendidikan (STKIP) \\ Perguruan Tinggi Budidaya Binjai
}

\begin{abstract}
This research aims to analyze the religious values contained in the novel When Mas Gallant Go work Helvy Tiana Rosa. The object of research is novel titled When Mas Dashing Go. The method used is descriptive qualitative method. Mechanical research using data analysis techniques to determine the religious values contained therein. The research data in this novel are quotations in the form of words and sentences in the novel When Mas Dashing Go. Techniques used in data collection documentary studies. The research instrument is the researchers themselves as the main instrument. The results of his research is the value of human piety towards God, man's obedience to our fellow human beings and human obedience to himself.
\end{abstract}

Keywords : Novel, values, religious.

\section{PENDAHULUAN}

Kajian sastra sebenarnya hal unik yang menyenangkan untuk dibahas. Banyak para pakar mendefinisikan makna sastra itu sendiri. Dalam kamus istilah sastra disebutkan bahwa sastra adalah tulisan dalam arti luas, umumnya berupa teks rekaan, baik puisi maupun prosa yang nilainya tergantung pada ekspresi jiwa. Ini berarti yang dikatakan sastra adalah segala sesuatu yang diutarakan dalam teks sebagai wadahnya yang diekspresikan dalam wadah tersebut adalah cerita-certia rekaan sebagai karya dari manusia sebagai penulisnya.

Sementara itu sastra juga dapat diartikan sebagai suatu bentuk dan hasil pekerjaan seni kreatif yang objeknya adalah manusia dan kehidupannya dengan menggunakan bahasa sebagai mediumnya. Pendapat tersebut dikemukakan oleh M.Atar Semi. Dari pendapat tersebut yang kita sarikan bahwa sastra selalu menggunakan media bahasa dalam penyampaianya. Selain itu yang dikisahkan dalam sastra tentunya adalah semua kisah manusia dan kehidupannya. Karya sastra bisa dikatakan indah jika di dalamnya memiliki nilai-nilai kehidupan, baik nilai budaya, sosial, pendidikan, religius dan lainnya. Salah satunya nilai religius (keagamaan).

Perkembangan suatu karya di Indonesia sangat maju, hal tersebut bisa dilihat dari pengarang dan isi cerita yang sangat beragam. Salah satunya novel yang 
bertemakan keagamaan, Seperti novel Ketika Mas Gagah Pergi. Novel ringan dan yang menghibur ini memiliki tebal 258 halaman. Novel Ketika Mas Gagah Pergi dipilih penulis karena novel ini dikemas sangat menarik, menghibur, Banyak hikmah yang dapat diambil dari membaca novel tersebut. Novel ini berharga untuk dibaca, karena dapat memperkaya cara pandang tentang agama, kehidupan, dan kehormatan. Helvy Tiana Rosa sebagai penulis di dalam novel tersebut sangat apik dan mudah dicerna pembaca isi novelnya. Novel ini nantinya akan difilmkan di layar lebar dan akan tayang pada tanggal 21 Januari 2016.

Testimoni dari Habiburrahman Elshirazy (penulis novel best seller, Ayat-Ayat cinta dan Ketika Cinta Bertasbih) mengatakan bahwa novel ini adalah kisah yang akan membangun jiwa dan karakter pemuda islam Indonesia. Asma Nadia (Penulis bukubuku best seller Indonesia) juga berkomentar tentang novel ini, Ketika Mas Gagah Pergi sangat menginspirasi saya sebagai remaja saat itu dan membuat saya menjadi pribadi yang lebih peduli pada sekitar serta lebih mencintai islam. Kisah ini abadi dan mampu mengubah pembacanya menjadi lebih baik.

Tujuan dari penulisan makalah ini yaitu untuk memahami nilai-nilai religius yang terkandung dalam novel Ketika Mas Gagah pergi. Rumusan masalah dalam makalah ini. Apa yang dimaksud nilai religius ? Bagaimana nilai religus yang terdapat dalam novel tersebut?

Novel merupakan bentuk dari sebuah karya sastra. Novel biasanya menceritakan tentang kisah hidup manusia dalam berinteraksi dengan lingkungan dan sesamanya. Karangan prosa yang panjang, mengandung rangkaian cerita kehidupan seseorang dengan orang-orang disekelilingnya dengan menonjolkan watak dan sifat setiap pelaku. Dalam sebuah novel, si pengarang berusaha semaksimal mungkin untuk mengarahkan pembaca kepada gambaran-gambaran realita kehidupan melalui cerita yang terkandung dalam novel tersebut. Selanjutnya menurut Lailasari dan Nurlailah novel merupakan cerita fiksi dalam bentuk tulisan atau kata-kata dan mempunyai unsur instrinsik dan ekstrinsik ${ }^{1}$.

Nilai adalah sifat-sifat (hal-hal) yang penting dan berguna bagi kemanusiaan ${ }^{2}$. Sedangkan agama ialah berasal dari bahasa sansekerta yang erat hubungannya dengan Hindu dan Budha. Akar kata agama adalah gam yang mendapat awalan a dan akhiran a

\footnotetext{
${ }^{1}$ Laelasari dan Nurlailah.2008. Kamus Istilah Sastra. Bandung: Nuansaaulia. Hal 166

${ }^{2}$ Departemen Pendidikan Nasional.2008. Kamus Besar Bahasa Indonesia Pusat Bahasa.Jakarta : PT Gramedia.
} 
sehingga menjadi a-gam-a. Bahasa sansekerta yang menjadi asal perkataan agama, termasuk rumpun bahasa Indo-Jerman, serumpun dengan bahasa Belanda dan Inggris. ${ }^{3}$

Religius adalah pengikat diri kepada Tuhan, atau lebih tepatnya manusia menerima ikatan itu justru karena ikatan itu dialami sebagai sumber kebahagiaan, sehingga terselenggaralah kepentingan, sekaligus tercapailah integrasi, pembentukan baru dari pribadinya. Nurgiyantoro mengemukakan bahwa kehadiran unsur religius dan keagamaan dalam sastra adalah setua keberadaan sastra itu sendiri, bahkan sastra tumbuh dari suatu yang bersifat religius. Religius sering dikonotasikan pada makna agama. Religius dan agama memang erat kaitan dan hubungannya, namun keduanya mempunya makna yang berbeda ${ }^{4}$.

Nilai religius secara konkrit di dalam penelitian ini yang menjadi persoalan pokok, yaitu nilai ketakwaan manusia terhadap Allah, nilai ketaatan manusia terhadap manusia, dan nilai ketaatan manusia terhadap dirinya sendiri. Ketiga hal ini merupakan bentuk dari religiusitas langsung. Dikatakan langsung karena, berhubungan erat dengan bagaimana suatu nilai ketakwaan manusia terhadap Tuhan, terhadap sesama manusia dan dirinya sendiri termasuk di dalamnya bagaimana sikap dan tindakan yang dilakukan terhadapNya.

Alasan peneliti memilih novel Ketika Mas Gagah Pergi karya Helvy Tiana Rosa sebagai objek penelitian. Pertama, dalam novel ini terdapat banyak sekali nilainilai religius, terutama nilai ketakwaan manusia terhadap Allah SWT, nilai ketakwaan terhadap sesama manusia dan nilai ketaatan terhadap diri sendiri, setelah membaca novel ini berulang-ulang. Kedua, Novel ini merupakan karya Helvy Tiana Rosa yang sudah berulang kali dicetak dan akan diangkat ke layar lebar pada tanggal 21 Januari 2016 , mendapat tanggapan positif dari masyarakat. Ketiga, dalam novel ini terdapat suatu nilai kehidupan yang banyak mengajarkan hubungan kedekatan dengan Allah dan sesama manusia.

Novel Ketika Mas Gagah Pergi ditulis Helvy Tiana Rosa yang diterbitkan pertama kali oleh AsmaNadia Publishing House, sekarang sudah cetakan keempat 2014 di Depok, setebal 258 halaman. Helvy Tiana Rosa menyelesaikan S1 dan S2 di Fakultas Sastra/Fakultas Ilmu Budaya, Universitas Indonesia. Selain dikenal sebagai sastrawan, dosen berprestasi Unversitas Negeri Jakarta tahun 2008 ini telah menulis

\footnotetext{
${ }^{3}$ Lestari,Lisa Esi. 2013. Artikel Nilai Religius dalam Novel Dalam Mihrab Cinta Karya Habiburrahman El Shirazy, Jurusan PBS. Hal : 3-

${ }^{4}$ Nurgiyantoro,Burhan.1995. Teori Pengkajian Fiksi.Yogyakarta: Gajah Mada University Press.
} 
lebih dari 50 buku, antara lain Juragan Haji (2014), Tanah Perempuan (2009), Segenggam Gumam (2003) dan Mata Ketiga Cinta (2012). Helvy pernah mendapat 30 penghargaan tingkat nasional di bidang penulisan dan pemberdayan masyarakat, antara lain Anugerah Sastra dari Balai Pustaka dan Majalah Sastra Horison (2013), Tokoh Perbukuan IBF Award dari IKAPI (2006), Tokoh Sastra Eramuslim Award (2006) Ummi Award ( 2004), Kartini Award sebagai salah satu The Most Inspiring Women in Indonesia (2009) dan Helvy merupakan satu dari 500 tokoh muslim paling berpengaruh di Dunia hasil riset Royal Islamic Strategic Studies Centre, Jordan selama lima tahun berturut-turut (2009,2010,2011,2012,2013,2014).

Penelitian ini membatasi pada nilai-nilai religi yang terkandung dalam novel Ketika Mas Gagah Pergi karya Helvy Tiana Rosa. Novel ini banyak mengandung nilai religius, terutama nilai ketakwaan manusia terhadap Allah SWT, nilai ketakwaan manusia terhadap manusia dan ketaatan manusia terhadap dirinya sendiri. Penelitian tentang analisis nilai religius pada novel pernah dilakukan oleh Lisa Esi Lestar, nilai religius dalam novel dalam Mihrab Cinta Karya Habiburrahman El Shirazy.

\section{METODOLOGI PENELITIAN}

Metode yang digunakan dalam penelitian ini adalah metode deskriptif yaitu penelitian yang mengungkapkan fakta sebagaimana apa adanya. Penelitian ini mengungkapkan kata-kata dan kalimat yang bukan berupa angka-angka. Disajikan melalui kutipan-kutipan kalimat yang berkaitan dengan masalah penelitian dalam novel Ketika Mas Gagah Pergi karya Helvy Tiana Rosa.

Data dalam penelitian ini adalah kutipan-kutipan berupa kata-kata maupun kalimat dalam novel Ketika Mas Gagah Pergi sesuai dengan kriteria nilai-nilai religi yang telah dirumuskan pada bagian masalah penelitian. Sumber data dalam penelitian adalah novel Ketika Mas Gagah Pergi yang diterbitkan oleh AsmaNadia Publishing House cetakan keempat tahun 2014 di Depok setebal 258 halaman.

Teknik pengumpulan data yang digunakan dalam penelitian ini adalah teknik studi dokumenter yakni mengumpulkan data dari teks novel. Adapun langkah-langkah teknik pengumpulan data pertama, membaca novel Ketika Mas Gagah Pergi secara cermat dan berulang-ulang. Kedua, Mencatat bagian-bagian yang berkaitan langsung

\footnotetext{
${ }^{5}$ Lestari,Lisa Esi. 2013. Artikel Nilai Religius dalam Novel Dalam Mihrab Cinta Karya Habiburrahman El Shirazy, Jurusan PBS. Hal : 3-4
} 
dengan masalah yang akan dianalisis. Ketiga, mengklasifikasikan atau mengelompokkan data sesuai dengan masalah penelitian, yaitu nilai ketakwaan manusia terhadap Allah, ketaatan manusia terhadap manusia, dan nilai ketaatan manusia terhadap dirinya sendiri. Keempat mendeskripsikan data sesuai dengan klasifikasi masalah peneliti, yaitu nilai ketakwaan manusia terhadap Allah, ketaatan manusia terhadap manusia, dan nilai ketaatan manusia terhadap dirinya sendiri,

Alat pengumpul data yang digunakan dalam penelitian ini adalah peneliti sendiri sebagai instrument dapat memahami teks dan konteks novel. Kedudukan penulis sebagai instrument utama dalam penelitian ini, yaitu perencana, pelaksana, pengumpul data,penganalisis, penafsir data dan pelapor hasil penelitian dalam novel Ketika Mas Gagah Pergi karya Helvy Tiana Rosa.Teknik yang digunakan dalam menganalisis data, yang pertama, data yang sudah siap dianalisis, kedua, mengelompokkan data sesuai dengan masalah penelitian, yaitu nilai ketakwaan manusia terhadap Allah, ketaatan manusia terhadap manusia, dan nilai ketaatan manusia terhadap dirinya sendiri. Ketiga, Memberikan makna yang berkaitan dengan rumusan masalah mengenai nilai ketakwaan manusia terhadap Allah, ketaatan manusia terhadap manusia, dan nilai ketaatan manusia terhadap dirinya sendiri, Keempat, menarik simpulan dari data yang sudah dianalisis.

\section{HASIL PENELITIAN DAN PEMBAHASAN}

Ketakwaan manusia terhadap Allah

Berikut ini merupakan nilai religius yang dilihat dari ketakwaan manusia terhadap Allah.

"Membawakan oleh-oleh sepulang sekolah dan mengajariku mengaji”. (hal :2).

Kutipan diatas menunjukkan kata "mengaji” merupakan bukti dari pelaksanaan ibadah kepada Allah. Mengaji merupakan mempelajari Al-Qur'an dan ilmu agama Islam.

Mas Gagah dalam pandanganku adalah sosok ideal . Kombinasi yang unik dari banyak talenta . ia punya rancangan masa depan . tapi tak takut menikmati hidup. Ia moderat tapi tak pernah meninggalkan sholat (hal :3)

Kutipan di atas memperlihatkan bahwa Mas Gagah dengan kehidupannya yang modern namun ia tidak pernah meninggalkan sholat lima waktu. Sholat merupakan kewajiban seorang muslim dan tiangnya agama. 
“Mas ketemu kiai hebat di Madura,"cerita Mas Gagah antusias. "Namanya Kiai

Ghufron! Subhaallah, orangnya sangat bersahaja, santri-santrinya luar biasa!

Disana Mas memakai waktu luang Mas untuk mengaji pada beliau (hal :4)

Kutipan di atas menggambarkan bahwa Mas Gagah memanfaatkan waktu luangnya untuk belajar mengaji memperdalam ilmu agama kepada Kiai Ghufron, seorang Kiai hebat dari Madura. Kiai Ghufron la yang mengajarkan Mas Gagah banyak ilmu agama sehingga ia menjadi sosok pemuda yang soleh.

Di satu sisi kuakui Mas Gagah tambah alim. Shalat tepat waktu , berjamaah di mesjid, ngomongnya soal agama terus . Kalau aku iseng mengintip di lubang kunci, ia pasti lagi ngaji atau baca buku islam (hal :6)

Kutipan di atas menggambarkan Mas Gagah semakin alim dan soleh. Ibadah yang ia lakukan semakin bagus, seperti sholat tepat pada waktunya tidak pernah ada yang tinggal, selalu berjamaah di mesjid. Kalau berbicara sama Gagah pembicaraanya membahas masalah agama,ibadah. Orang yang sholat berjamaah di mesjid pahalanya lebih banyak dari pada sholat sendirian di rumah. Seorang laki-laki muslim lebih mulia sholat wajibnya berjamaah di mesjid,

Aku masih ingat jelas. Beberapa waktu yang lalu Mas Gagah mengajakku pengajian di rumah temannya. Terus pernah juga aku diajak menghadiri tabligh akbar di suatu tempat. (hal:8)

Kutipan di atas menggambarkan bahwa Mas Gagah benar-benar berdakwah mengajak kebaikan untuk adiknya, ia ajak untuk mau ikut ke pengajian, Tabligh Akbar dan memperdalam ilmu agama. Gagah ingin adiknya itu lebih dekat lagi dengan islam.

“ Mengapa saya memakai jilbab?. Alasan pertama karena berjilbab adalah perintah Allah dalam surat Al-Ahzab ayat 59 dan Annur ayat 31 . kedua karena jilbab merupakan identitas utama untuk dikenali sebagai seorang muslimah. Astri Ivo seorang artis, justru mulai menggunakan jilbab saat kuliah di Jerman. Saya alhamulillah mulai mengenakannya saat kuliah di Amerika. (hal:16).

Dari kutipan di atas menjelaskan bahwa memakai jilbab merupakan bukti ketaatan seorang muslimah terhadap Allah SWT. Hal ini diingatkan dalam Al-Qur'an surat Al-Ahzab ayat 59 yang berbunyi “ Wahai Nabi! katakanlah kepada istri-istrimu, anak-anak perempuanmu,dan istri-istri orang mukmin, hendaklah mereka menutup 
jilbabnya ke seluruh tubuh mereka yang demikian itu agar mereka lebih mudah untuk dikenal sehingga mereka tidak diganggu. Dan Allah Maha Pengampun dan Penyayang. Sedangkan surah An-Nur ayat 31 berbunyi Katakanlah kepada wanita yang beriman: "Hendaklah mereka menahan pandangannya, dan kemaluannya, dan janganlah mereka menampakkan perhiasannya, kecuali yang (biasa) nampak dari padanya. Dan hendaklah mereka menutupkan kain kudung kedadanya, dan janganlah menampakkan perhiasannya kecuali kepada suami mereka, atau ayah mereka, atau ayah suami mereka, atau putera-putera mereka, atau putera-putera suami mereka, atau saudarasaudara laki-laki mereka, atau putera-putera saudara lelaki mereka, atau putera-putera saudara perempuan mereka, atau wanita-wanita islam, atau budak-budak yang mereka miliki, atau pelayan-pelayan laki-laki yang tidak mempunyai keinginan (terhadap wanita) atau anak-anak yang belum mengerti tentang aurat wanita. Dan janganlah mereka memukulkan kakinyua agar diketahui perhiasan yang mereka sembunyikan. Dan bertaubatlah kamu sekalian kepada Allah, hai orang-orang yang beriman supaya kamu beruntung.

Wujud ketaatan mausia dengan sesama manusia

Berikut ini nilai religius yang dilihat dari wujud ketaatan manusia terhadap sesama manusia

Ia selalu mengajakku kemana ia pergi. Ia yang menolong saat aku butuh pertolongan (hal :2)

Kutipan di atas menjelaskan bahwa Mas Gagah peduli terhadap sesama, memberikan pertolongan disaat orang membutuhkan pertolongan.

Coba pakai jilbab, Git !"pinta Mas Gagah suatu ketika (hal :14)

Kutipan di atas menjelaskan bahwa Mas Gagah ingin adiknya juga soleha, taat beribadah kepada Allah menjalankan semua apa yang diperintahkan Allah. Oleh sebab itu Mas Gagah menyuruh Gita adiknya untuk memakai jilbab.

“ Sudah banyak perbaikan . yang jadi copet sudah tak ada. Yang jadi garong apalagi.Pis,Piss, Gagah. Terima kasih bimbingamu selama ini. (hal :20)

Kutipan di atas menggambarkan bahwa Mas Gagah memiliki jiwa sosialis yang tinggi. Banyak jasa yang sudah dilakukan oleh Gagah. Membimbing pata pencopet sehingga mereka insaf takut kepada Allah, sampai akhirnya mereka 
mendapatkan hidayah melalui jasa Gagah. Mas Gagalah yang selama ini sudah membimbing, mengarahkan dan mengajari mereka mengaji.

"Ibu Tanya, mau tidak kalian Ibu ajari membaca dan mengaji ?"aku tersenyum lembut. (hal :81)

Kutipan di atas menggambarkan bahwa si Ibu peduli terhadap sesama, mau meluangkan waktunya untuk mengajar ngaji dan membaca untuk anak-anak jalanan.

“ Ibu, Amir itu teman Tomi yang paling baik yang pernah Tomi Punya . Dia anak baik, Bu. Pemuda yang bagus keislamannya. Tomi banyak belajar darinya. Bukankah ibu yang mau Tomi berteman dengan pemuda yang alim... dan ini.... (hal :138).

Kutipan di atas menggambarkan sifat Tomi yang sangat baik kepada Amir, suka menolong. Sikap Tomi menunjukkan kepeduliannya terhadap sahabatnya yaitu Amir.

Ketaatan manusia terhadap dirinya sendiri

Berikut ini merupakan nilai religius dilihat dari ketaatan manusia terhadap dirinya sendiri.

Mas sedih Karena Allah, Rasul dan Al-Islam kini sering dianggap remeh . Sedih Karena umat yang banyak meninggalkan AlQur'an dan Sunnah juga terpecah belah. Sedih karena saat Mas bersenang-senang dan bisa beribadah dengan tenang, saudara kita di negeri sendiri banyak yang mengais-ngais makanan di jalan, dan tidur beratap langit, sementara di belahan bumi lainnya sedang diperangi (hal :12)

\section{KESIMPULAN}

Nilai ketakwaan manusia terhadap Allah yang terdapat pada novel Ketika Mas Gagah Pergi karya Helvy Tiana Rosa, yakni meliputi, Sholat, keyakinan kepada Allah, mengaji, dituntut utntuk berhijab bagi yang muslimah. Di dalam novel tersebut pembaca diajak untuk bertakwa kepada Allah dalam menjalani kehidupan ${ }^{6}$. Hal ini dapat diwujudkan dengan cara selalu mengerjakan sholat lima waktu, berdoa kepada Allah dan yakin kepada Allah SWT. Nilai ketaatan manusia terhadap sesama manusia dalam novel Ketika Mas Gagah Pergi meliputi, saling tolong menolong, mengingatkan

\footnotetext{
${ }^{6}$ Rosa,Helvy Tiana.2014. Ketika Mas Gagah Pergi. Depok : AsmaNadia Publishing House.
} 
dalam kebaikan, saling nasehat menasehati. Nilai ketaatan manusia terhadap diri sendiri, yakni tentang keistiqamahan dan memelihara kehormatan diri.

\section{DAFTAR RUJUKAN}

Departemen Pendidikan Nasional.2008. Kamus Besar Bahasa Indonesia Pusat Bahasa.Jakarta : PT Gramedia.

Lestari,Lisa Esi. 2013. Artikel Nilai Religius dalam Novel Dalam Mihrab Cinta Karya Habiburrahman El Shirazy, Jurusan PBS. Hal : 3-5.

Laelasari dan Nurlailah.2008. Kamus Istilah Sastra. Bandung: Nuansaaulia.

Nurgiyantoro,Burhan.1995. Teori Pengkajian Fiksi.Yogyakarta: Gajah Mada University Press.

Rosa,Helvy Tiana.2014. Ketika Mas Gagah Pergi. Depok : AsmaNadia Publishing House. 